\title{
DELPHI STUDIES: THE VALUE OF EXPERT OPINION BRIDGING THE GAP-DATA TO KNOWLEDGE
}

\author{
Dr Arthur Winzenried, \\ Information Manager/Librarian, \\ Lilydale Adventist Academy, Australia \\ Email: arthurw@ozonline.com.au
}

\begin{abstract}
This paper reports an as yet unfinished Delphi investigation of information management futures. Too often the personal aspect of information provision is overlooked in the light of the dramatic development of technology. However, behind every technological advance there is a provider whose role it is to source, organise and disseminate the information gleaned via that technology.

To investigate what is at heart a very subjective situation-an individual's reaction to a changing work place-the Delphi approach seemed most appropriate. Designed to collect expert opinions as independent, considered views on a commonly debated topic, this method offered structure and validity without a framework too formal to allow for personal, subjective considerations.

A Delphi approach provides a unique methodology for studying the trend of future developments. In this particular study it demonstrated a clear perception by senior members of the profession as to the future.
\end{abstract}

\section{INTRODUCTION}

Crucial to the growing strains on traditional information provision is the current state, or perhaps the everchanging state, of technology. It now appears that data managers need to be intensively technological. Cost factors within education circles, the changing nature of curriculum and training programmes of the immediate past combine to limit financial and skill support to staff. The ever-increasing stock of online data and its attendant selection difficulties further challenge the providers. What then is the future of the Teacher-Librarian/ Library Media Specialist?

To investigate this, a Delphi study was carried out in conjunction with the Charles Sturt University, New South Wales. All discussion rounds were completed by January 1997 at which time detailed assessment of the responses was made. This process is based on the theory that by coalescing and analysing a variety of expert opinion, some predictions can be made regarding the future. Based on these predictions it is possible to provide meaningful direction for the present as well as future training of staff towards that end result. It is a process of considerable value and assistance in the analysis of more subjective material-in this case, aspects of information handling staff, their role, present and future.

Among those participating in the process were prominent data provision figures from seven countries (USA, UK, Australia, Iceland, New Zealand, Denmark, Canada), including representatives of several branches of data provision-academic (including Clyde, Eisenberg, Dillon, Haycock, Lupton, Myklebust, Oberg), information practitioners (including Johnson, Clausen, Grey, Bonanno) and institutional (including Clouten, Lisle, Milbury, Walker, Lockwood).

\section{The Nature of the Beast}

Delphi studies are not new. They stem from developments in the 1960s. "In 1969 the number of Delphi studies that had been done could be counted in three digits; today, in 1974, the figure may have already reached four digits." (Linstone \&Turoff, 1975) Since that time a considerable number of Delphi studies have been carried out with government departments in Japan (New Scientist, 1993, October 2, p.3) to assess future economic trends, in Britain for Science and Technology forecasting (Times Higher Education Supplement, 1995, March 24, p.15) and in the 
United States for similar technology forecasting (see, for example, Doyle 1992; USA Today 1995, May, p.85.).

The Delphi technique is designed to collect opinions from a group of experts in a given discipline. By collecting these opinions, resubmitting them a number of times and providing continuous feedback with each new round of consideration, a satisfactory consensus may be reached. This consensus may be considered as a relevant and valid measure of the future in that it is the summation of the collected opinions of experts.

Christine Doyle (1992) presented a study of information literacy in America. Her analysis employed the same methodology as does the present study. Using Delphi method, she attempted to reach some consensus as to a definition of information literacy in the light of American national education goals. As a part of American development and the National U.S. Forum on Information Literacy (NFIL), the study was a stepping stone towards greater emphasis on the importance of information literacy as a vehicle towards successful outcomes in education.

What was made more clear in the Doyle study was that the Delphi technique was highly appropriate for the study, particularly in the light of its not easily permitting a more formal methodology. She identified several reasons why this was the case. Among these was the need in her study of a consensus regarding a definition of information literacy, the broad diversity of backgrounds over which such a consensus had to be gained and the inherent value of "subjective judgements collectively discussed" to her topic (Doyle, 1992, p. 38). Some of these factors exist in the present study suggesting the value of the technique for this particular project.

The literature on Delphi investigations of information management is sparse. The present work is very indebted to a project carried out in Denmark by Helge Clausen in 1991-92 (Clausen, 1992). Clausen's work concentrated on the Internet and its attendant Computer-Mediated Communications aspects but his methodology, modified from that suggested in Linstone and Turoff (1975), has formed the basis for the present methodology.

A Delphi is largely a "structuring of human communications." (Linstone \& Turoff, 1975, p. 6) In this regard its philosophy has never been closely defined. Attempts by Helmer and Rescher (1989) and Scheele (in Linstone \& Turoff, 1975, p. 37ff) highlight the "reality" of collected assumptions as a suitably secure basis on which to formulate future predictions. Scheele notes that interaction and impact within a group dynamic produces a collection of realities which are a "significant" result in themselves (Linstone \&Turoff, 1975, p. 40). The success and validity of the Delphi process is very much dependant on concepts of "common reality" so it becomes important to ensure that any study using this approach seeks to identify these realities. Part of the process then becomes concerned with seeking reality views, exploring agendas and gestalts, identifying latent options and issues, explaining and extracting from the collected views and from this collected data, generating a common or consensus reality picture.

An exploration with these goals in mind, which considers the collected "realities" of a group of individuals, each with considerable knowledge of their field, is by a process of consensus, most likely to yield a series of realities. Upon these realities, then, can be built some assumptions of the future. Within the Delphi process too, is an element of group identity. In the case of most Delphi processes this identity is more with the topic than with other individuals in the group. Keeping an element of anonymity directs panel attention to the topic and for this reason, the present study has chosen the anonymous approach.

In summary, "each Delphi interaction produces a shared reality which is initially formulated by the panellists from their expectations ... this particular reality is elaborated and modified by the succeeding interactions." (Lindstone \& Turoff, 1975, p. 64)

Of considerable importance are two characteristics of Delphi method. These, outlined in Linstone and Turoff (1975, pp. 191-321) are the lack of a generally positive relationship between group size and group performance and the decreasing variance of responses with each progressive round of discussion. This latter aspect is most clearly seen from about the third round.

The first consideration is important in that it allows a panel of as few as fifteen can still yield meaningful conclusions (Martyn \& Lancaster, 1981, p. 62). The second is important as it produces some manageable "result." 


\section{In Practice}

The actual Delphi process utilised for the present study followed the suggested practices outlined in the work of Lindstone and Turoff (1975, esp. p. 39ff). Three major rounds of discussion was allowed following an initial limited round to quickly assess the general topic and some suggested approaches (a more detailed methodology is provided below). As an important part of the process several aspects of methodology were considered to be most important.

The issue of anonymity was considered of primary importance. There was no provision in the current study for collusion between team members although most would have been aware of the identity of some names in particular. Following each round of considerations, comments made and arguments put forward were recirculated among the team without names being attached. This was a deliberate attempt to concentrate team members on their views of major developments as well as the fundamental arguments without allowing them to be deflected by another members perceived academic stature, experience or location. Thus, the tendency to judge only those developments suggested by the most notable panellists was largely eliminated by virtue of anonymity.

The group of experts is not a random sample and cannot be treated as such. Despite this, the number is important as is the spread. While conventional statistical analysis cannot be applied to the Delphi sample and the method is largely intuitive/qualitative it is important that the results may lead to quantitative findings. Kristensen (1990) lists four important advantages of the Delphi system. The method promotes vision, is well suited to new ways of thinking and innovation, makes possible an analysis free from historical ties and finally, it is an economical means of analysis provided the choice of panel members is carried out with care. Importantly, although a Delphi study is a unique phenomenon and consequently unreproducible, its findings may nevertheless be reliable and be useable in forecasting (Clausen, 1992, p. 188).

\section{Method-Specific}

The present study was initially planned so as to carry out the Delphi part of the investigation in eight specific stages. These covered the initial formation of the team through to final synthesis of the results and discussions which took place. Each stage is very briefly outlined below.

Stage A. Initial request for members; completed February 1996.

Stage B. Check on members for team balance. February 1996. Request from each member for statement of:

- Current position

- Qualifications.

- Experience in information/data management/resource provision

- Self perception of current role; e.g., administrator, practitioner, etc.

- Suggested topic with issues to be clarified. Definitions, limits, time covered by study.

Stage C. Round 1. Initial topic discussion. April, 1996. Circulate topic with discussed definitions, etc, included. Discussion by each member.

Stage D. Analysis 1: May, 1996. Consider and relate each response. Gather points of consensus and divergence. Note any areas of confusion arising from misunderstandings, or cultural differences, etc. Formulate a Round 2 statement showing the consensus and divergence clearly as well as introducing new considerations which were made relevant by first round debate. Fringe issues, related matters, etc. Indicated where these fit into the field of study suggested under Stage B.

Stage E. Round 2 Debate: June, 1996. Discuss relevant issues and outcomes of Round 1 as summed up in Stage D. Leading questions here should highlight convergence and divergence shown in the first round to attempt some further consensus among the team. Relevant fringe issues shown up in Round 1 should also be included.

Stage F. Analysis of Round 2; July, 1996. Like that following Round 1, analysis at this stage should look carefully at areas of agreement and disagreement to the end of locating points of consensus. It may be useful at this stage to check statistically on levels of deviation between participants in the first and second rounds so as to identify the "Delphi effect" and thus assist with authentication of the 
whole process. Presence of the effect at this stage will help emphasise the validity of the team and the process. Lack of clear Delphi effect may well indicate some areas are in which the process is not reflecting correct Delphi practice.

Stage G. Round 3: August, 1996. Final discussion time for the group participants. Final attempt must be made in framing the round discussion material to finding a suitable consensus, summation of matters arising from the first two rounds so as to finally check participants are satisfied that the material reflects their views. Final clarification of issues, fringe issues, and related matters. Clear identification of time line arising from debate e.g., "By 1997..."; "By 1998 ...," etc. Produce matters such as implications of the findings, viz., "if...by 1998, then why not...now?"; "if ... by 1999 then should we set up different training programmes?"

Stage H. Final Analysis and Presentation of Findings. Synthesis of all responses, analysis of results, validity of the whole programme and its participants. Points of consensus, irreconcilable differences, etc. Together with an examination of how and why these came about.

\section{First Impressions}

First impressions of the process were exciting to say the least. The concept of actually canvassing the opinions of professionals and experts intimately acquainted with the field presented quite a challenge. Essentially, the process lived up to the high expectations. Discussion has been considerable, the input from each team member was at times prodigious and the final result surprisingly unanimous, though not wildly radical.

This was potentially one of the more interesting aspects considered in the first instance. Talking with others who had run Delphi studies, some had gained very clear and complete outcomes, others had ended with very indecisive conclusions. The results seemed to be quite unpredictable. As an initial expectation I had pondered the possibility of the profession being sufficiently coherent as to make a more decisive conclusion most likely. This was certainly the case. A decision reached by almost thirty people from seven different countries which only saw one major dissenter, must be rather unusual. It does demonstrate a very coherent view of the profession and a very clear view of intended (or foreseen) future directions.

\section{On Methodologies}

Definition. One problem that besets the investigator in the information field is that of definition. What's in a name? There is an important issue here. Terminology can sometimes obstruct the view and sideline effective consideration of this important issue. In the educational context one often hears of Teacher-Librarians or Media Specialists. In the more open field of business one can occasionally refer to Information Manager or Data Manager in much the same context. For the purposes of this study reference was made generically to a person whose primary task it is to collect, catalogue and disseminate information effectively from many sources to users with many needs.

Method. One further difficulty which was not fully perceived initially but which has definitely affected the outcome has been the sheer volume of the input. In rounds following the first, members input had to be drastically edited to make communication possible. It was simply out of the question to circulate more than 100 typed pages of discussion material each round. In an ideal world the entire group would have been able to peruse the entire discussion material but in reality, many of the team members were hard pressed reading the edited material as it was.

\section{CONCLUSION}

The most significant result of this study has been undoubtedly, the unanimous outcome. In the final analysis, nine statements or premises emerged to which all but one member subscribed. These are:

- While technology has impacted on Teacher-Librarian activity, the core functions of teaching information processes, evaluation and communication remain. Access to greater amounts of information has increased both the extent of the task and its importance. 
- Stress is present for the Teacher-Librarian of the future both in terms of learning curve and of greater expectations. There is increased public pressure to perform and a greater financial role ahead for most Teacher-Librarians.

- Future technical trends in the profession focus on digital technology and some degree of virtual library development. These trends will only increase the need for personal tuition and close teacher-librarian/client (student) liaison.

- Future non-technical trends in the profession focus on teaching of process (not product), on curriculum involvement and in greater time outside library "walls" collaborating with general teaching staff.

- Future "devices" that will impact on teacher-librarian activity will include (probably in order of appearance):

internet

multimedia

intelligent agent

virtual reality

Some of these are already present and influential.

- One future problem is likely as a direct result of technology; there will be a widening gap between the resource "haves" and "have nots." Inequity will be a hallmark of libraries in 2006. Sharing resources freely may go some way toward easing this problem.

- Essential areas of future teacher-librarians activity include (from highest to lowest priority):

$$
\begin{aligned}
& \text { information literacy } \\
& \text { client support/interaction } \\
& \text { information management } \\
& \text { computer skills } \\
& \text { lobbying and advocacy } \\
& \text { managing change }
\end{aligned}
$$

- Educational administrators, to ensure best resourcing results, should integrate resources with learning most intimately. Teacher-librarians should become whole school teachers often outside identified library "walls." Resourcing should be clearly recognised as central to successful education and curriculum delivery-budgeting and staffing should reflect this.

- Teacher-librarians will require more adequate technical support in the future. Efficient administrations will recognise this and provide same.

One aspect of methodology requiring attention is actual phraseology. This study attempted to investigate, not the role of teacher-librarians generally but only that part of their role which was impacted by technology. Clearly, the actual words used in a process of this sort are more important than they are in a spoken communication as each correspondent has time to consider them in depth.

\section{REFERENCES}

Clausen, H. (1992). Electronic mail and the information professional. Hornslet, Denmark.

Doyle, C. (1992). Development of a model of information literacy outcome measures within national education goals of 1990. Unpublished thesis, Northern Arizona University.

Helmer, O. \& Rescher, N. (1989). On the epiestemology of the inexact sciences. Management Science 6, (1).

Henri, J. (Ed.) (1992), Collaborative teaching and learning. Waga Waga, NSW 
Linstone, H. \& Turoff, M. (1975). The delphi method: Techniques and applications. Reading, MA.

Winzenried, A. (1996a, August). Imagine the possibilities. The Electronic Library.

Winzenried, A. (1996b). Future information provision: Burnout, boom or bust? Hong Kong Proceedings.

Winzenried, A. (1996c). Information mangers of the future, prophet, priest or poohbah. London Online Proceedings, pp.7ff. 